\title{
Research on Road Environment Construction of Pavement Management System
}

\author{
Langrong $\mathrm{Ai}$ \\ School of construction management \& real estate \\ Chongqing University \\ Chongqing 400045, China, \\ E-mail:1872098545@163.com
}

Dewen Liu

School of civil engineering

Southwest Forestry University

Kunming 650000, China,

E-mail:fangdichan@163.com

\author{
Dong Liu \\ School of civil engineering \\ Southeast University \\ Nanjing 410000, China, \\ E-mail:heshirong@sina.com \\ Shidong Zeng \\ School of civil engineering \\ Southwest Forestry University \\ Kunming 650000, China, \\ E-mail:nihaomalaoda@126.com
}

\begin{abstract}
Reviews the historical development of road project management system is presented in this paper, based on the connotation, the core management of road projects all over the world are in detail described, the problems of road engineering project management system has carried on the countermeasure analysis, finally, the trend of the future of the road project management system has carried on the outlook, the article has significance on road project management workers. The article studied the road environment at the same time, discusses the pavement project engineering management for the influence of road environment .
\end{abstract}

Keywords-Pavement ; Management ;bridge; innovation; engineering

A specialized pavement testing equipment, which is developed and utilized in France, may collect large amount of various data on pavement and road conditions and will estimate the whole road system every three years. An ultimate goal of France is to apply this pavement management system to ascertain pavement maintenance method and provide all information on pavement condition.

Pavement testing equipment in South Africa uses the latest techniques, computer programs and global location technique. The collected information is used to inspect road systematic condition, predict pavement service life and select maintenance project program in future. Cost efficiency of pavement maintenance work can be confirmed by well-designed procedures.

Pavement management system applies two-step processing program to generate various strategies and further optimize it, and optimizer may help to select the cost-optimal maintenance strategy under given budget indexes. Even though pavement management system confirms an optimum strategy, a final construction operational plan shall be selected through on-site investigation, and then this selection shall be examined and estimated and the final project program will be modified to satisfy local need and conditions.

Various data collection systems have been used in all states of Australia. The collected data involves flatness, track, strength, structure, crack, frictional resistance and life of seal coat. An internally used software developed in Queensland has been used as state and local strategic support tool to road maintenance policy and strategy; regarding other states, commercially provided corresponding software are used to complete similar work.

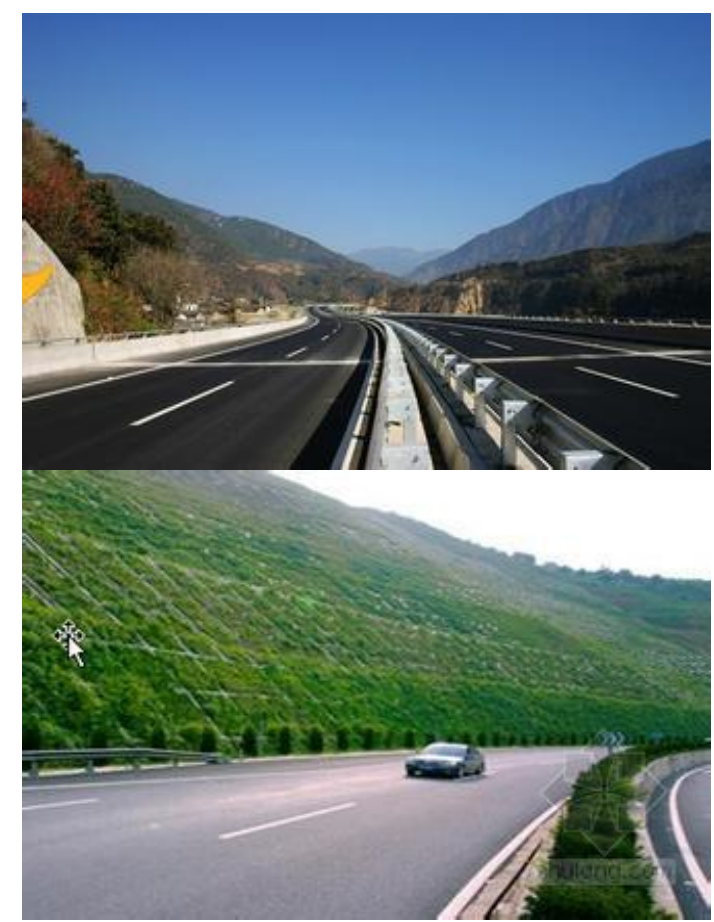

Figure1. Highways engineering instance

Even the most well-designed asphalt pavement system can't escape the effects of Mother Nature. Facility owners and managers are often challenged with making financial decisions on how to implement a program that's best suited for their needs. One such need is to lessen the impact of the environmental forces that degrade pavement.

Local pavement maintenance contractors can provide guidance on the selection of preventive maintenance menu items, but how do you know what the right option is, and if 
it's the right time to perform this work? Preventive maintenance strategies that may be appropriate for one situation may not be appropriate for another.

Pavement that is appropriate for preventive maintenance applications includes systems that are relatively new, when preservation of the pavement system remains cost effective. These pavement systems will generally be 3 to 7 years old, and may be experiencing the early stages of deficiencies, such as surface raveling and pavement cracking. Protecting asphalt pavement systems from environmental factors, such as water penetration into the base through cracks and fissures, along with oxidation of the pavement's upper surface, can add years to the life of the pavement system. Preventive maintenance isn't effective for pavement that exhibits structural deficiencies or failures.

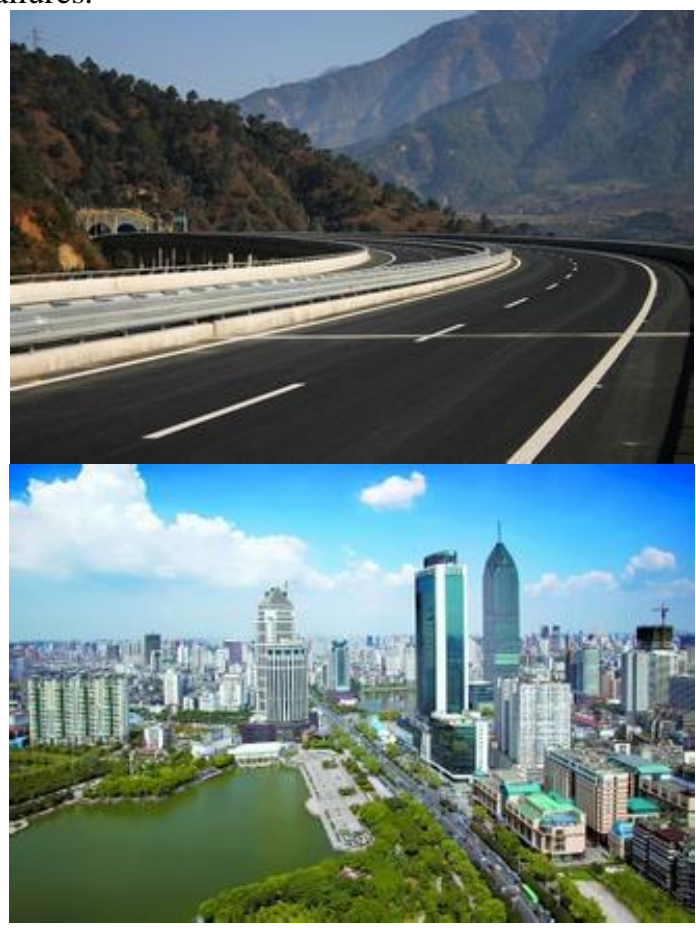

Figure2.Highways harmonious

As a facility owner or manager, the objective of protecting your pavement investment should start with planning a pavement-management program. The approach for parking-lot-asphalt pavement-management programs should always include cracksealing as a preventive maintenance measure. Crackfilling is one alternative to consider, and it has a distinctly different meaning.

Crackfilling typically refers to the process of blowing out and cleaning cracks prior to installation of a crackfiller material. This is also known as the "blow-and-go" method. If properly done, crackfilling reduces the infiltration of water into the crack, which protects the pavement system from being weakened by moisture. Crackfilling should be used for wider-type, non-working cracks.

Materials for crackfilling can be asphalt emulsions, asphalt cements, fiberized asphalt, or polymer-modified emulsions(listed in the general order of increasing material performance properties and costs).

Life expectancy for crackfilling applications is less than 3 years. This method provides benefits by preventing water intrusion through the crack, which can weaken the aggregate base and subgrade materials. If there are shorterterm expectations and considerations for major pavement rehabilitation in the next few years, crackfilling can be a lower-cost approach that meets these goals.

The cracksealing process involves an additional step that's highly recommended for longer-term performance, and involves routing of the crack. Cracksealing includes grinding out the crack to a wider, 0.5 -inch to 0.75 -inch by 0.75 -inch square, providing a reservoir for the rubberized crackseal material.

This reservoir provides greater flexibility during thermal changes, especially freeze-thaw cycles. Overbanding the rubberized crackseal material over the top of the crack completes the cracksealing process Overbanding is sometimes omitted from this process based on local preferences and type of use. If done properly by keeping the thickness of the band less than 0.125 inches in depth, good performance results can be achieved for parking-lot applications.

Materials for cracksealing can be asphalt rubber or rubberized asphalt. Rubberized asphalt materials are the most commons, and they're designed for specific temperature ranges. Be sure the product is designed for, and has a history of performance in, the climate in which the project is located. Some material prodects can be identified as"parking-lot-grade'material. Materials such as these can sacrifice long-term performance characteristics for the sake of returning the parking lot to service faster with less tracking of the quicker-setting material. Due to these limitations, don't assume this will be the best product for your needs.

Knowing the distinction of the cracksealing process can add additional life to the pavement while providing further benefits in preventing water intrusion into the system. Life expectancies of 3 to 5 years should be expected for cracksealing applications.

As always, a qualified contractor with a track record of similar successful project should be used for cracksealing as a first step in implementing a preventive maintenance program. Cracksealing is one of the most cost-effective means of extending the life expectancy of pavement.

As a proactive facility owner or manager, the next obvious question is: "what else can I do to assure that I'm getting the greatest return on my asphalt investment?"

Surface-treatment applications are more complicated than cracksealing; pavement conditions and their end use will influence the type of application. These two issues are further compounded by the climate in which the pavement is located. The fundamental benefit for the application of a surface treatment is to extend the life expectancy and performance of the pavement. It's important to understand the different types of surface treatments, and that it's not the function of a surface treatment to provide any structural improvement.

Project management is the core of cost management, to establish the responsibility cost management system and operation mechanism, as the center of the project cost management, the company responsible for the overall control of the aim of the contract costs. Through decomposition of contract price, adjustment, comprehensive, balanced, determine if the internal accounting unit price, puts forward instructional target cost 
plan, cost of operation and management of the work layer guidance and supervision; Secondary units operating layer is responsible for executive management to develop the target cost decomposition of target, in strict accordance with the internal accounting control unit price cost consumption, self-financing. Chief engineer is responsible for organizing technical personnel optimization of construction scheme, improve the technical measures, encourage artisans to carry out technological innovation and technological innovation, to provide technical support for the effective cost control. Chief economist based on contract, to organize the formulation of the construction cost budget plan, determine the target cost of the project, and is responsible for the layers of decomposition and supervise cost performance. Chief accountant on operation of the project cost and actual consumption condition, to the project construction cost accounting and cost analysis, calculation and reflect the project profit and loss, check whether the cost control target, and summing up the experience of the cost control. In order to ensure construction quality, importance to undertake to the worker quality education, strengthening the quality consciousness. Oath to carry out quality activities, and achieve the wake-up call. Set up quality control system of heavy penalties amply rewarded with iron wrist, tough spirit and the iron discipline to ensure the construction quality. In responsible for severe punishment of quality accidents at the same time, set up big bonuses, to reward good quality price and personal. To better the quality department and quality inspection personnel should play the role of supervision, improve the qc inspectors sense of responsibility and sense of honor, establish archives construction quality management system, to carry out the quality responsibility system for life. May improve the level of computer application Improve the management level, realize modernization management, it is necessary to application of computer, the computer is the important tool of enterprise management modernization. Project from the bidding to the completion of the acceptance, besides must have a higher level of construction technology, and advanced modern construction management method should be adopted to improve the level of enterprise management, the management must rely on the computer to complete. Practice has proved that using the computer aided management is an effective way to improve the level of construction enterprise management. A specialized pavement testing equipment, which is developed and utilized in France, may collect large amount of various data on pavement and road conditions and will estimate the whole road system every three years. An ultimate goal of France is to apply this pavement management system to ascertain pavement maintenance method and provide all information on pavement condition.

Each year city and country officials are asked to deal with winter road maintenance problems with less funding, personnel and equipment.

In addition to the economic pressure, there are also concerns about some of the traditional methods of snow and ice control. Concerns have surfaced about the environmental impact of using salt and sand for winter maintenance. Sand may cause air pollution - due to airborne particulates - and salt, in addition to damaging pavement and vehicles, may also cause problems for roadside vegetation and groundwater quality.

A recent survey of Iowa cities and counties identified some interesting strategies for dealing with winter road maintenance. Much of the data from the study covers current practices and includes issues such as snow policy documents.

A number of cities and counties have snow policy documents that specify the procedures to be followed when clearing snow and ice from roads. These documents are critical when contractors perform a majority of work and when court cases arise over accidents on icy roads. If a city or country has a policy in place and can document that it has been followed, this can be of great benefit in court.

These documents categorize roads to be cleared based on a number of factors. The most critical roads are specified to be cleared within a certain time frame-typically four to six hours - after the end of a storm. Other roads are given lower priority, and the document may specify that certain road categories only be cleared during regular working hours.

Another new method of winter road maintenance is anti-icing, which aims to get chemicals on the road prior to a storm. Results from the Strategic Highway Research Program (SHRP) indicate that anti-icing provides the same level of service as more conventional methods of snow and ice control yet uses a much smaller quantity of chemicals.

There is also new equipment, including new shapes of cutting edges developed under the SHRP program, that is being successfully tested in the filed. In-cab computers that provide information on blade angles and pressures are also being seriously considered. Studies are also being conducted on ways to reduce accident-causing snow cloud formation behind plowing trucks.

There is also a move toward testing new equipment before it id selected. Testing would allow officials to determine whether a piece of equipment would do what it is supposed to or whether it would be cost-effective.

There is lot happening in winter road maintenance right now. Snow may fall, and roads may freeze in the same old ways. But the methods of clearing those roads will change.

A key part of pavement management system-road condition analysis is a yearly visualized estimation on basis of national standards, which assure uniformity in estimated results by each province though training and qualification authentication on reviewers. The yearly estimation is always integrated with mechanical measurement in order to count on road condition indexes. The mechanical measurement on road is made once every 2 to 3 years, which includes inspection on horizontal and vertical section of roads. The road condition indexes are used on counting of optimum formulation of preventive maintenance on basis of existing capital scale.

\section{ACKNOWLEDGMENT}

The First author is Longrong Ai, The Corresponding author is Dewen Liu. 


\section{REFERENCES}

[1] I. S. Jacobs and C. P. Bean, "Fine particles, thin films and exchange anisotropy," in Magnetism, vol. III, G. T. Rado and H. Suhl, Eds. New York: Academic, 1963, pp. 271-350.

[2] K. Elissa, "Title of paper if known," unpublished.

[3] R. Nicole, "Title of paper with only first word capitalized," J. Name Stand. Abbrev., in press.

[4] M. Young, The Technical Writer's Handbook. Mill Valley, CA: University Science, 1989.

[5] Stackelberg H. The Theory of the Market Economy. Oxford: Oxford University Press, 1952.

[6] Miller,T., Friesz,T. \& Robin,R., Heuristic algorithms for delivered pric spatially competitive network facility location problem. Ann. Oper. Res., 34,pp.177-202,1992.
[7] Pieume, C.O, Fotso L.P. \& P. Siarry. A method for solving bilevel linear progremming problem. Journal of Information and Optimization Science, 29(2), pp. 335-358,2008.

[8] J. Clerk Maxwell, A Treatise on Electricity and Magnetism, 3rd ed., vol. 2. Oxford: Clarendon, 1992, pp.68-73.

[9] Electronic Publication: Digital Object Identifiers (DOIs):

[10] D. Kornack and P. Rakic, "Cell Proliferation without Neurogenesis in Adult Primate Neocortex," Science, vol. 294, Dec. 2001, pp. 2127-2130, doi:10.1126/science.1065467.

[11] H. Goto, Y. Hasegawa, and M. Tanaka, "Efficient Scheduling Focusing on the Duality of MPL Representatives," Proc. IEEE Symp. Computational Intelligence in Scheduling (SCIS 07), IEEE Press, Dec. 2007, pp. 57-64, doi:10.1109/SCIS.2007.357670. 